\title{
Electrochemical and corrosion resistance of new Ti-Mo-Fe alloys for biomedical applications
}

\author{
Y. M. Abd-elrhman ${ }^{1}$, M. A. Gepreel ${ }^{1}$, A. Abd El-Moneim ${ }^{1}$ \\ \& S. Kobayashi ${ }^{2}$ \\ ${ }^{1}$ Department of Materials Science and Engineering, \\ Egypt-Japan University of Science and Technology, Egypt \\ ${ }^{2}$ Department of Materials Science and Engineering, \\ Ehime University, Japan
}

\begin{abstract}
Titanium and its alloys have been used extensively in the last few decades as materials for orthopedic and dental implants and other medical devices due to their high strength, low modulus, and high corrosion resistance in biological media. Besides other important material features, the corrosion parameters and corrosion products are responsible for limiting the biocompatibility of metallic materials, and can produce undesirable reactions in implant-adjacent and/or more distant tissues. Electrochemical corrosion behaviors of novel beta titanium alloys, Ti4.7Mo- $-5.5 \mathrm{Fe}$, Ti-3Mo- $0.5 \mathrm{Fe}$ and $\mathrm{Ti}-2 \mathrm{Mo}-0.5 \mathrm{Fe}$ were investigated in naturally aerated Ringer's solution at room temperature compared with currently used biomedical titanium alloy, Ti-6Al-4V. Very low current densities were obtained from the potentiodynamic polarization curves, indicating a passive behavior for all the studied alloys. Electrochemical impedance spectroscopic (EIS) studies showed high impedance values for all samples indicating an improvement in corrosion resistance of the spontaneous oxide layer. The fitting data obtained suggests a single passive layer form on the virgin surfaces of the alloys. The EIS results exhibited capacitive behavior (high corrosion resistance) with phase angles close to $-80^{\circ} \mathrm{C}$ and high impedance values at low and medium frequencies, which are indicative of the formation of a highly stable film on these alloys in the test solution. The new present alloys are promising metallic biomaterials for the future, owing to their very low elastic modulus and good corrosion resistance capabilities. Keywords: titanium alloys, corrosion resistance, Ringer's solution.
\end{abstract}




\section{Introduction}

More than two thirds of implants are made of metallic biomaterials i.e. stainless steel, cobalt (Co)-chromium ( $\mathrm{Cr}$ ) alloys, and titanium (Ti) and its alloys. Among these metallic biomaterials $\mathrm{Ti}$ alloys exhibits the highest biocompatibility, corrosion resistance and specific strength (ratio of strength to density), compared with the other metallic biomaterials [1]. Recently, researchers gave much attention to develop low rigidity $\beta$ and near $\beta$ type titanium alloys composed of non-toxic and non-allergic elements with excellent biocompatibility, superior corrosion resistance, high strength and low elastic modulus (close to that of human bone). The relatively low modulus of $\beta$ and near- $\beta$ titanium alloys may also reduce the "stress-shielding" effect [2-6]. Although, titanium alloys possess a set of suitable properties for biomedical application, but its corrosion resistance property still plays a vital role in this kind of application. Whereas, the corrosion products are largely responsible for the biocompatibility and can cause inflammations with the implant-adjunct tissues. Therefore, corrosion resistance investigation is considered one of the in-vitro evaluation procedure for the acceptance these alloys as biomaterial. Fortunately, titanium and its alloys show high corrosion resistance due to the spontaneous formation of a protective oxide film of 1-4 nm thickness [7] on its surface at open circuit conditions. In the physiological fluids, that contain about 1 wt. $\% \mathrm{NaCl}$, the present Chloride can destroy the oxide film, so it is necessary to investigate the durability and stability of these passive films in simulated body fluids [8].

Ti-4.7Mo-4.5Fe, Ti-3Mo-0.5Fe, and Ti-2Mo-0.5Fe are a set of new beta titanium alloys developed to be used as biomaterials. The present work is undertaken to study the corrosion behaviour of the investigated alloys, as well as compare its performance with the commercial alloys such as Ti-6Al-4V to judge on its performance and its ability to be used as biomaterials. Although there are many alloys used as biomaterials but they still have high cost, so the candidate's materials are presented as low cost biomaterials

\section{Experimental procedure}

\subsection{Materials preparation}

Nominal composition of Ti-4.7Mo-4.5Fe, Ti-3Mo-0.5Fe, and Ti-2Mo-0.5Fe (in atom \%) alloys were arc-melted with a tungsten electrode on a water-cooled copper hearth. Titanium blocks were melted to purify the Ar gas atmosphere before the Ar-arc melting. All the ingots of the alloys were melted and inverted six times in order to promote their homogeneities. Specimens were solid-solutiontreated (ST) at $1173 \mathrm{~K}$ in $\beta$ phase field for $3.6 \mathrm{ks}$ followed by rapid quenching into ice water. The designed alloys were selected to be investigated and characterized from the point view of corrosion to judge on their performance as biomaterials. 


\subsection{Electrochemical evolution}

Electrochemical experiments were conducted in two standard cells, namely, polarization cell and reference cell, connected by salt-bridge probe. The polarization cell contained the working electrode and a platinum wire as a counter electrode, while the reference cell contained the standard saturated $\mathrm{KCl} \mathrm{Ag} / \mathrm{AgCl}$ reference electrode. Working electrolyte was a naturally aerated aqueous Ringer's physiological solution. Ringer's solution has an electrolyte composition closer to that of plasma as compared to normal saline, this solution composed of $0.32 \mathrm{~g}$ $\mathrm{CaCl}_{2} .2 \mathrm{H}_{2} \mathrm{O}, 0.3 \mathrm{~g} \mathrm{KCl}, 8.6 \mathrm{~g} \mathrm{NaCl}$, and quantum sufficed of water for each $1000 \mathrm{~mL}$ of electrolyte, the measured $\mathrm{pH}$ for the solution was 5.4. Prior to any immersion, the working electrodes were grinded using 2000 grade silicon carbide paper and rinsed with distilled and deionized water. All electrochemical measurements were managed by a Princeton Applied Research potentiostate and controlled by a personal computer with dedicated software (VersaSTAT 4). In order to verify the reproducibility of electrochemical results, all experiments were repeated three times measured at the same sample, after a new polish for the surface of the working electrode and good reproducibility was observed.

Measurements of the open-circuit potential, OCP, for each composition were performed on the polished samples, until the potential values became reasonable stable. The corrosion potential was measured as a function of time for about $116 \mathrm{~min}$. with a stability of about $0.005 \mathrm{mV} / \mathrm{s}$.

Potentiodynamic polarization studies were carried out after $7000 \mathrm{~s}$ of immersion in Ringer's solution after reaching almost to the steady state. Potentiodynamic polarization measurements were performed in the potential range from $-500 \mathrm{mV}$ in the cathodic direction to $1600 \mathrm{mV}$ in the anodic direction from open-circuit potential (OCP) vs. $\mathrm{Ag} / \mathrm{AgCl}$ reference electrode at a scan rate of $0.167 \mathrm{mV} / \mathrm{s}$. The corrosion potential $\left(\mathrm{E}_{\text {corr }}\right)$ and corrosion current density $\left(\mathrm{i}_{\text {corr }}\right)$ were determined from the polarization curves using Tafel extrapolation method.

Electrochemical impedance spectroscopy (EIS) measurements were carried out at open-circuit potential and the impedance spectra were acquired in the frequency range from $100 \mathrm{kHz}$ to $100 \mathrm{mHz}$. The applied alternating potential signal had an amplitude of $10 \mathrm{mV}$. EIS plots were obtained after the specimens solution treated at $900^{\circ} \mathrm{C}$. Data acquisition and analysis were performed with a personal computer. The spectra were interpreted using the ZSimpWin software. Impedance data were represented in Bode amplitude and phase angle plots. The charge transfer resistance (Rs) and double-layer capacitance (CPE) values were determined. The Bode representation shows the logarithm of the impedance modulus ( $\log Z)$ and phase angle as a function of the frequency logarithm (log frequency).

\subsection{Corroded surface}

To characterize the anodic oxide films formed on the surface of specimens, the specimens were ultrasonically cleaned methanol after the potentiodynamic polarization tests and then examined by the optical microscope. 


\section{Results and discussion}

\subsection{Open-circuit potential analysis}

The open-circuit potential (OCP) is the potential at which the specimen is in equilibrium with the surrounding environmental. The open-circuit potential of metals always measured as a function of time, until it stabilizes at a stationary value after a certain period of immersion. The open-circuit potential is used as a criterion for the corrosion behavior. This type of measurements is qualitative and still insufficient for a complete electrochemical analysis.

The results obtained from the open-circuit potential (OCP) with immersion time in Ringer's solution are presented in Fig. 1 and Table 1 for the studied alloys and at the different heat treatment conditions. As it can be seen from Fig. 1, the potentials increase quickly during the first few minutes and then shift slowly in the more noble direction, until it reaches a quasi-stationary values. This behavior is indicative on the spontaneous formation and growth of the oxide film on the surfaces of the samples. Furthermore, the OCP in the noble direction indicates that an oxide film is passivating the metallic surface [9], suggests that a protective passive film acts as a barrier for metal dissolution, reducing the corrosion rate. AlMobarak [10] in his research gave another interpretation for the appearance of the initial shift of potential during the first few minutes, he claimed that the first shift is due to the dissolution of the pre-immersion oxide layer that formed in air before immersing the samples in the solution.
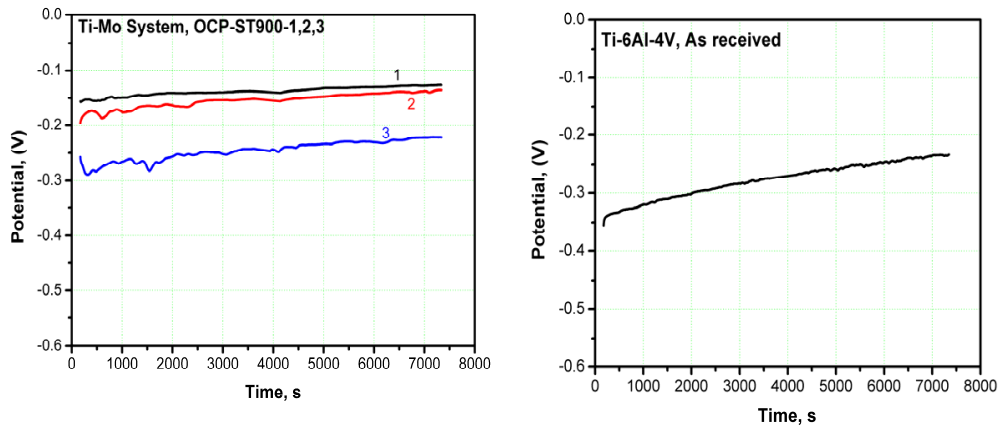

Figure 1: Open-circuit potential (OCP) versus time in Ringer's solution of Ti-4.7Mo-4.5Fe (denoted as “1”), Ti-3Mo-0.5Fe (denoted as “2”), Ti-2Mo-0.5Fe (denoted as "3"), and Ti-6Al-4V.

From the OCP profiles, a comparison among the obtained quasi-stationary OCP values for the specimens at different heat treatment conditions can be carried out. There is a clear evidence on the effect of the heat treatment process through the variation of OCP values. As a result of solution treatment process (ST900) after the hot rolling process (HR900), all the OCP values for all studied compositions were towards to the noble direction; this result indicates that the spontaneous oxide film formed on the alloys due to the solution treatment process displays better 
corrosion protection characteristics than the oxide film formed on hot rolled samples. By comparing the obtained results of the OCP of the studied compositions with the OCP of most widely used titanium alloy in the biomedical applications, Ti-6Al-4V, one can notice that the oxide film on the studied samples formed more rapidly than Ti-6Al-4V. Nevertheless, they are mostly agree in the direction towards the noble direction.

Table 1: Open-circuit potentials at the steady state conditions for Ti-4.7Mo-4.5Fe (denoted as "1"), Ti-3Mo-0.5Fe (denoted as “2”), Ti-2Mo-0.5Fe (denoted as “3”), and Ti-6Al-4V in Ringer's solution.

\begin{tabular}{|l|l|}
\hline \multicolumn{2}{|c|}{ Heat treatment process ST900 } \\
\hline Samples & {$[O C P / m v$ vs. $\mathrm{Ag} / \mathrm{AgCl}]$} \\
& $-129 \pm 7$ \\
(1) Ti-4.7Mo-4.5Fe & $-139 \pm 13$ \\
$(2) \mathrm{Ti}-3 \mathrm{Mo}-0.5 \mathrm{Fe}$ & $-223 \pm 17$ \\
(3) $\mathrm{Ti}-2 \mathrm{Mo}-0.5 \mathrm{Fe}$ & $-233 \pm 15$ \\
*Ti-6Al-4V & *Ti-6Al-4V used only for comparison and did not subject to any heat \\
treatment process (used as received). \\
\hline
\end{tabular}

It is clear from the above OCP results that the heat treatment process is a strong factor on the electrochemical performance of the metals. These values of the OCP can be interpreted in the light of the present microstructures due to the heat treatment process. The type of the present crystal structure i.e., hcp ( $\alpha$-phase), bcc ( $\beta$-phase), orthorhombic $\alpha^{\prime \prime}$...etc. influences on the number of dislocations leading to the difference in the mechanical properties of the alloys. The difference of the mechanical properties i.e., ductility, strength and so on, due to the heat treatment will of course effect on the electrochemical properties such as OCP. The formed $\beta$-phase as a result of the solution treatment process effected on the OCP values of the alloys and directed them towards the noble direction. Therefore, the more dense phase is present, the more reduction in the corrosion rate.

Potentiodynamic polarization studies Fig. 2 shows the potentiodynamic polarization curves for the studied alloys compared with Ti-6Al-4V as tested in Ringer's solution at $25^{\circ} \mathrm{C}$. Potentiodynamic polarization studies were conducted in the potential range of $-500 \mathrm{mV}$ to $+1600 \mathrm{mV}$ with respect to OCP vs. $\mathrm{Ag} / \mathrm{AgCl}$ for all alloys. From these curves, the corrosion parameters, i.e. the corrosion potential $\left(\mathrm{E}_{\text {corr }}\right)$, corrosion current density $\left(\mathrm{i}_{\text {corr }}\right)$, were obtained from the Tafel region, then the corrosion current density was used to determine the corrosion rate for all alloys. The corrosion current density is representative for the degradation degree of the alloy. A distinctive passivation region was observed on the anodic polarization curves for all the studied alloys. This region of passive film formation was studied through the passivation current density ( $\left.\mathrm{i}_{\text {pass }}\right)$ which obtained around the middle of the passive range. It was observed from Fig. 2 that, the shape of the polarization curves is quite similar, while different corrosion parameters were 
determined for all alloys after heat treatment, see Table 2. This qualitative analysis of the polarization curves shows that the studied alloys have good potential to be used as biomaterials. The corrosion behavior of the present new alloys shifts towards nobility, i.e. the corrosion potentials, $\left(\mathrm{E}_{\text {corr }}\right)$ shift towards positive values and corrosion currents, $\left(\mathrm{i}_{\text {corr }}\right)$ decrease compared to Ti-6Al-4V. Our new alloys exhibits very high resistance for corrosion compared with one of the most used biomaterial, Ti-6Al-4V. The corrosion parameters of the present new alloys are about ten times better than that of Ti-6Al-4V and this clearly indicate that these alloys have excellent pitting and crevice corrosion resistance.

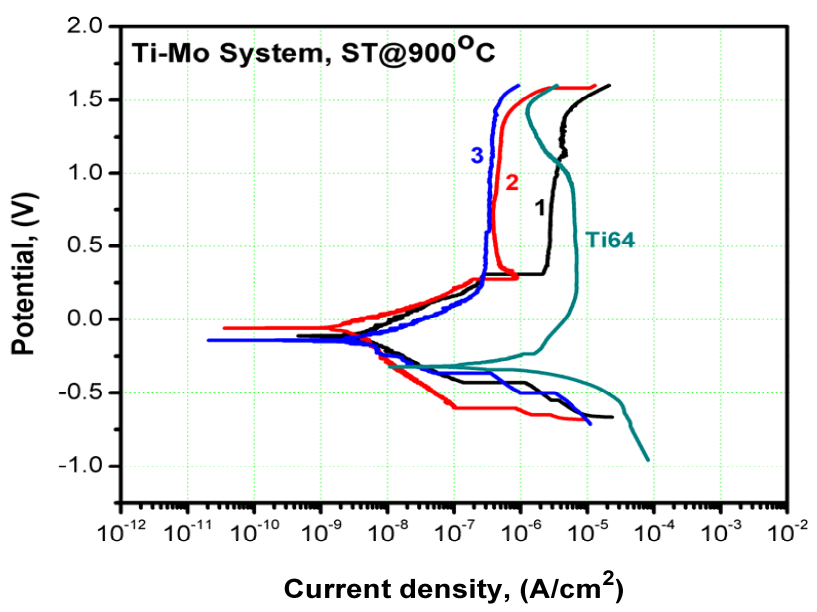

Figure 2: Potentiodynamic polarization curves for Ti-4.7Mo-4.5Fe (denoted as "1"), Ti-3Mo-0.5Fe (denoted as "2") and Ti-2Mo-0.5Fe (denoted as "3") after the heat treatment compared with Ti-6Al-4V (as received) in Ringer's solution at room temperature.

The corrosion rates were obtained from the corrosion current densities using the following equation (ASTM Standard G102-89 [11]):

$$
\text { Corrosion rate (in } \mu \mathrm{m} / \text { year) }=3.27 \mathrm{icorr} / \rho \mathrm{EW}
$$

where, icorr is the corrosion current density in $\mu \mathrm{A} / \mathrm{cm}^{2}, \rho$ the density $\left(4.51 \mathrm{~g} / \mathrm{cm}^{3}\right)$ and the $\mathrm{EW}$ is the equivalent weight for titanium alloys $\mathrm{EW}=($ atomic weight $(47.9)) /($ the valence (4) ). The calculated corrosion rates for the new present alloys at various heat treatments are tabulated in Table 2 . The value of the corrosion rate is the significant parameter that gives valuable information about the real behavior of the corrosion. Whereas the corrosion rate directly proportional with the corrosion current density so they have the same trend. In conclusion, the present new alloys are more resistance for corrosion compared with the most wide used biomaterial, Ti-6Al-4V. 
Table 2: Corrosion potential (Ecorr), Current density (icorr) and Passivation current density (ipass) determined from the polarization curves for Ti-4.7Mo-4.5Fe (denoted as "1"), Ti-3Mo-0.5Fe (denoted as "2") and Ti-2Mo-0.5Fe (denoted as "3") after the heat treatment process compared with Ti-6Al-4V (as-received) in Ringer's solution at room temperature.

\begin{tabular}{|c|c|c|c|c|c|}
\hline \multicolumn{4}{|c|}{ Potentiodynamic characterization } \\
\hline Compositions & $\begin{array}{c}\text { Heat } \\
\text { treatment }\end{array}$ & $\begin{array}{c}\text { Ecorr } \\
{[\mathrm{mv} v \mathrm{~s} .} \\
\mathrm{Ag} / \mathrm{AgCl}]\end{array}$ & $\begin{array}{c}\text { icorr } \\
{\left[\mathrm{nA}^{\mathrm{A}} \mathrm{cm}^{2}\right]}\end{array}$ & $\begin{array}{c}\text { ipass } \\
{\left[\mu \mathrm{A} / \mathrm{cm}^{2}\right]}\end{array}$ & $\begin{array}{c}\text { Corrosion } \\
\text { rate } \\
{[\mu \mathrm{m} / \text { year }]}\end{array}$ \\
\hline 1 & ST900 $^{\mathrm{a}}$ & -110 & 6.876 & 2.804 & 0.060 \\
\hline 2 & ST900 & -64 & 3.338 & 0.3915 & 0.029 \\
\hline 3 & ST900 & -138 & 5.838 & 0.3449 & 0.051 \\
\hline Ti-6Al-4V & $\begin{array}{c}\text { As- } \\
\text { received }\end{array}$ & -319 & 661.8 & 6.561 & 5.746 \\
\hline
\end{tabular}

Impedance (EIS) results of studied alloys were represented through the Bode plots as shown in Fig. 3. All specimens exhibit no significant change in their behavior. This result could be due to a complete coverage of the surface of newly formed spontaneous oxide layer. In this paper, a satisfactory fit of all data could obtain using simple equivalent circuit $R_{s}\left(Q R_{p}\right)$, see Fig. 4 , where $\mathrm{R}_{\mathrm{s}}$ and $\mathrm{R}_{\mathrm{p}}$ are the solution and the oxide film resistances, respectively. While, $Q$ is the constant phase element (CPE), which indicating on the capacitive behavior of the film. It can be seen in Table 3 that all compositions have very small capacitance values and the values of n almost near 1 , so $Q$ presents an almost pure capacitive behavior. For the oxide film resistance, $R_{p}$ (Table 3 ) has the same order of magnitude, $10^{5} \Omega . \mathrm{cm}^{2}$, and this high values demonstrated that the spontaneous formed oxide layer on the alloys is highly stable and resistive layer.

Table 3: Values of the equivalent circuit parameters derived from the fitting of the impedance data measured for the passive film grown spontaneously on the studied alloys, using the equivalent electric circuit $R_{s}\left(Q R_{p}\right)$, from Fig. 4.

\begin{tabular}{|c|c|c|c|c|}
\hline Compositions & $\mathrm{R}_{\mathrm{s}}\left(\Omega . \mathrm{cm}^{2}\right)$ & $\mathrm{Q}\left(\mathrm{S} \mathrm{cm}^{-2} \mathrm{~s}^{\mathrm{n}}\right)$ & $\mathrm{n}$ & $\mathrm{R}_{\mathrm{p}},\left(\Omega . \mathrm{cm}^{2}\right)$ \\
\hline 1 & 24.45 & $7.13 \times 10^{-5}$ & 0.844 & $1.54 \times 10^{5}$ \\
\hline 2 & 22.22 & $4.10 \times 10^{-5}$ & 0.825 & $7.53 \times 10^{5}$ \\
\hline 3 & 29.63 & $3.92 \times 10^{-5}$ & 0.835 & $4.06 \times 10^{5}$ \\
\hline
\end{tabular}



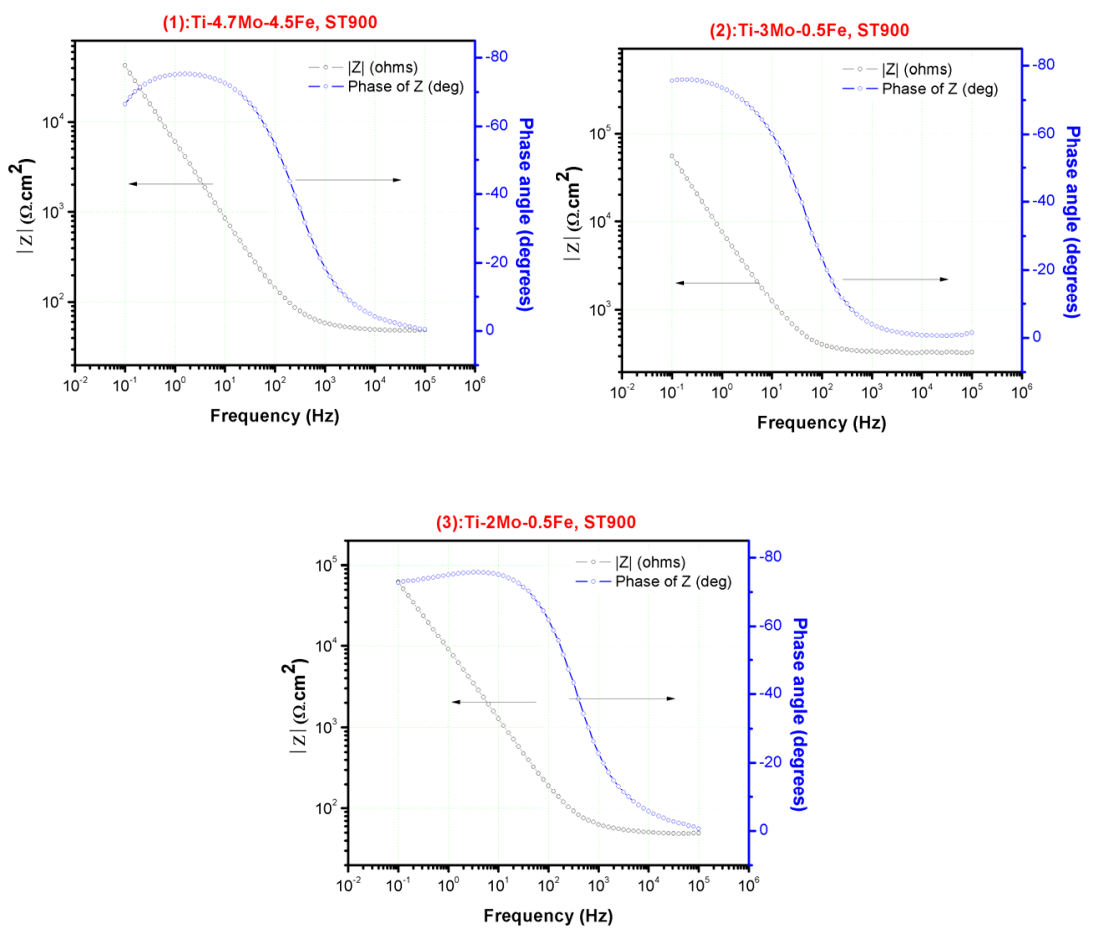

Figure 3: Bode diagrams of the studied alloys after solution treatment process at $900^{\circ} \mathrm{C}$ : (1) $\mathrm{Ti}-4.7 \mathrm{Mo}-4.5 \mathrm{Fe}$, (2) Ti-3Mo-0.5Fe and (3) Ti-2Mo$0.5 \mathrm{Fe}$.
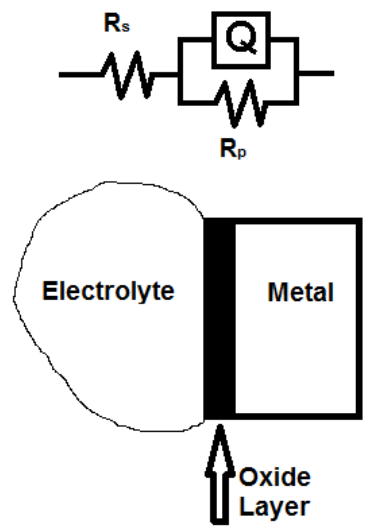

Figure 4: Equivalent circuit, used for fitting the experimental data. 


\subsection{Corroded surfaces evaluation}

5 shows the optical microscope (OM) micrographs of the passive oxide films formed on the surfaces of the designed alloys. The OM micrographs are in agreement with the above anodic curves whereas the morphologies of anodic films critically depend on the behavior of the oxide layer growth. The oxide layer formed on the surfaces of the specimens after solution treatment depends on the composition of the specimen. For all studied compositions, passivation occurred and the very small corrosion rates gives good indication on the promises of the candidate alloys as biomaterials.
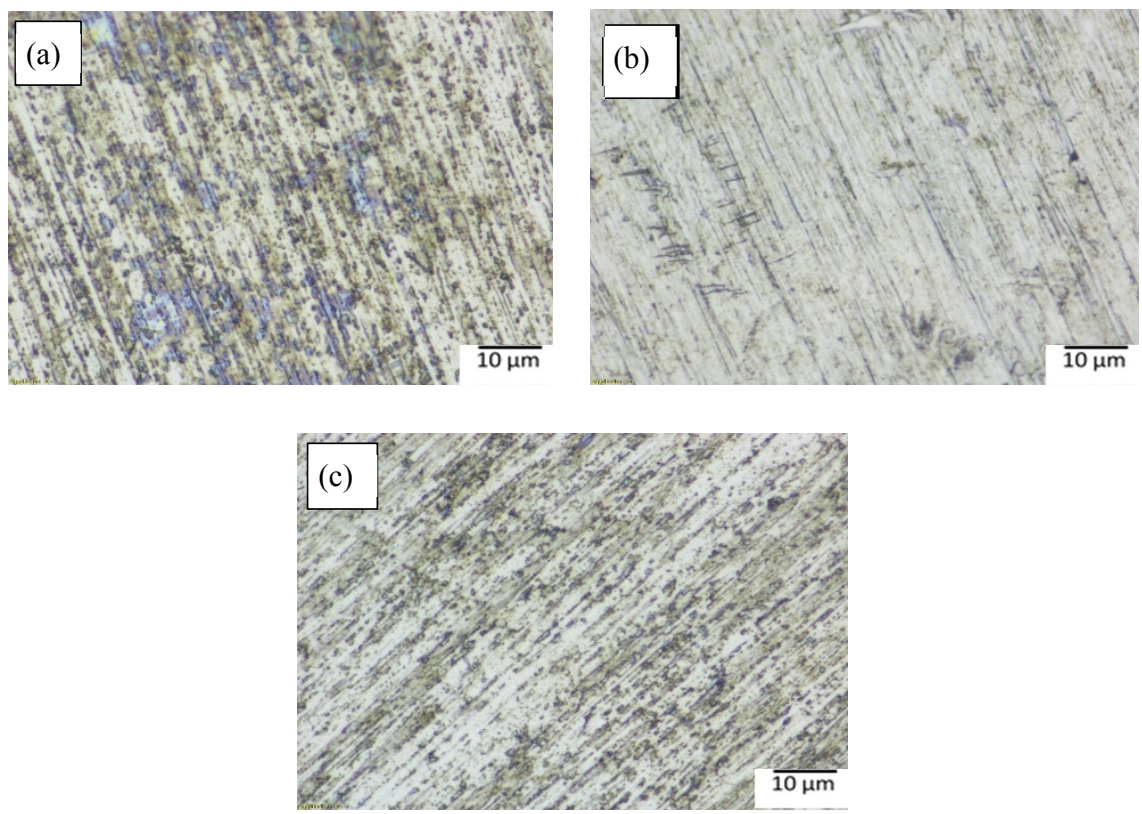

Figure 5: Optical microscope micrographs of oxide films on the surfaces of the studied alloys after anodic test: (a) Ti-4.7Mo-4.5Fe, (b) Ti-3Mo-0.5Fe and (c) Ti-2Mo-0.5Fe.

\section{Conclusions}

In this study, new titanium-iron based alloys were developed using low cost alloying element, Iron, to reduce to the total cost of the product. Two beta stabilizer elements were used in our alloys, Mo and Fe; electrochemical properties of these alloys were studied. The main results are summarized as follows:

- The open circuit potentials (OCP) of the designed alloys in the Ringer's solution directed towards the positive direction and reached to almost steady state condition within $30 \mathrm{~min}$. The short time which taken to reach 
the steady state is a good evidence on the stability of the formed oxide layer.

- The potentiodynamic tests after the solution treatment shows very low corrosion rates for the present alloys.

- High impedance values were obtained for all studied alloys, the obtained fit suggests a single passive film present on the metals' surface.

All these electrochemical results are connected and suggest that Ti-Mo-Fe alloys are promising materials for the biomedical applications, because their electrochemical stability.

\section{References}

[1] Niinomi, M., Nakai, M. \& Hieda, J., Development of new metallic alloys for biomedical applications. Acta Biomater, 8, pp. 3888-3903, 2012.

[2] Lütjering, G. \& Williams, J.C., Titanium (Engineering Materials and Processes). Springer, pp. 5-20, 2007.

[3] Oliveira, N.T.C., Aleixo, G., Caram, R. \& Guastaldi, A.C., Development of Ti-Mo alloys for biomedical applications: Microstructure and electrochemical characterization. Mater Sci Eng A, 452-453, pp. 727-731, 2007.

[4] Donachie, J.M., Titanium: A Technical Guide. ASM International, 2000.

[5] Dewidar, M.M., Yoon. H. \& Lim J.K., Mechanical Properties of Metals for Biomedical Applications Using Powder Metallurgy Process: A Review. Met Mater Int, 12, pp. 193-206, 2006.

[6] Geetha, M., Singh, A.K., Asokamani, R. \& Gogia, A.K., Ti based biomaterials, the ultimate choice for orthopaedic implants - A review. Prog Mater Sci, 54, pp. 397-425, 2009.

[7] Marino, C.E.B., Oliveira, E.M.D., Rocha-Filho, R.C. \& Biaggio, S.R. On the stability of thin-anodic-oxide films of titanium in acid phosphoric media. Corros Sci, 43, pp. 1465-1476, 2001.

[8] Alves, V.A., Reis, R.Q., Santos, I.C.B., Souza, D.G. \& Gonçalves, T., In situ impedance spectroscopy study of the electrochemical corrosion of $\mathrm{Ti}$ and $\mathrm{Ti}-6 \mathrm{Al}-4 \mathrm{~V}$ in simulated body fluid at $25^{\circ} \mathrm{C}$ and $37^{\circ} \mathrm{C}$. Corros Sci, 51, pp. 2473-2482, 2009.

[9] Oliveira, N.T.C. \& Guastaldi, A.C., Electrochemical stability and corrosion resistance of Ti-Mo alloys for biomedical applications. Acta Biomater, 5, pp. 399-405, 2009.

[10] Al-Mobarak, N.A., In situ impedance spectroscopy study of the electrochemical corrosion of orthopedic Ti-6Al $-7 \mathrm{Nb}$ in simulated body fluid. Adv Mater Lett, 3, pp. 433-440, 2012.

[11] ASTM G102-89, Standard Practice for Calculation of Corrosion Rates and Related Information from Electrochemical Measurements, 2004. 